\title{
Spectrum of Atypical Presentation of Tubercular Infections of Central Nervous System-Case Series and Review of Literature
}

\author{
Pankaj Sharma1,2 \\ ${ }^{1}$ Luanda Medical Center, Luanda, Angola \\ ${ }^{2}$ Formerly at SGRRHMS and SMI Hospital, Dehradun, India \\ Email: sharmapankaj29@gmail.com
}

Received 1 July 2015; accepted 7 September 2015; published 10 September 2015

Copyright (C) 2015 by author and Scientific Research Publishing Inc. This work is licensed under the Creative Commons Attribution International License (CC BY). http://creativecommons.org/licenses/by/4.0/

\section{(c) (7) Open Access}

\begin{abstract}
Tubercular infections of central nervous system commonly present with hydrocephalus, basal exudates, infarcts, tuberculomas, etc. However, rarely there are atypical lesions which can pose greater difficulty in differentiating from other lesions like tumors. This case series describes the spectrum of such lesions, with review few individual reports found in literature. Clinical presentations were weakness of limbs, slurring of speech and underlying primary tubercular focus. The age group ranged from 16 - 60 years with M:F ratio being 1:1. Spectrum of such lesions is discussed here with emphasis on the role of magnetic resonance imaging in prompt diagnosis. Thus initiating an early conservative line of management and its follow up with aversion of neurointervention which has its own inherent complications, the final outcome is a reduction in morbidity and mortality (as noted in the follow up) as well as patient cost care.
\end{abstract}

\section{Keywords}

CNS Tuberculosis, Tubercular Encephalitis, Tuberculoma, Isoniazid Induced Toxicity

\section{Introduction}

Tuberculosis is a common and deadliest disease in India (accounting for 24\% of total burden) and other developing nations of which more than half the cases (56\%) were in the South-East Asia and Western Pacific Regions. 
However, there is a slow decline seen each year as most deaths from TB are preventable (WHO/Global tuberculosis report 2014). Tuberculous infections of central nervous system commonly present with basal exudates, meningeal enhancement, hydrocephalus, infarcts and tuberculomas. These common findings may be lacking rarely in some patients which have CNS tuberculosis with atypical lesions. These lesions include tubercular encephalitis without meningitis, large intraparenchymal mass (tuberculoma), intramedullary spinal cord tuberculoma and isoniazid (antitubercular drug) induced cerebellitis. Since the treatment success rate is high, prompt diagnosis and follow up by imaging and laboratory methods is important. This study highlights the spectrum of rare atypical TB infections of the CNS with the role of magnetic resonance imaging, a noninvasive tool, in prompt diagnosis and follows up of these lesions, thereby early clinical management of such cases with a positive outcome.

\section{Case Series}

This study was done retrospectively by analyzing patients presenting with tubercular infections of the CNS (with an annual incidence of 30 - 50 cases), most commonly, tuberculous meningitis under the author in the last four years (2011-2015) in MRI department, among which only four definitely proven atypical tubercular lesions were identified and are discussed here. Two atypical lesions were excluded due lack of sufficient follow up.

The age group of patients ranged from 16 - 60 years and M:F ratio is 1:1. Two patients showed gradual, progressive symptoms and signs while the other two patients presented with acute symptoms. Two patients presented with gradually progressive limb weakness. One presented with a past history of tuberculoma with progressive weakness of left half of body with acute onset of hemiplegia. Another patient presented with acute onset of slurring of speech. Three patients had primary tubercular lesions located in Lungs, extracranial and intracranial sites respectively (prior to development of atypical TB lesions). MRI studies were done in all four atypical lesions. However no cerebro-spinal fluid analysis was performed by the treating clinicians.

The imaging was done on a 1.5 Tesla scanner (Siemens, Germany). The examinations included T1WI and T2WI spin-echo (SE) images completed with other image series for both brain and spine regions. Postcontrast study was done by injecting gadodamide IV, in adults as standard body dosage per kg body weight.

Four atypical tuberculous lesions were diagnosed on MRI imaging study (Table 1), including tubercular encephalitis without meningitis, large intraparenchymal tubercular mass, spinal intramedullary tuberculoma with characteristic TARGET sign and isoniazid induced drug toxicity.

Of the four definitely proven lesions, two were located in supratentorial regions, third was in spinal cord intramedullary region, and fourth was in infratentorial region. All these lesions were identified in immunocompetent patients. Three lesions were directly related to infective TB etiology with one lesion resulting from isoniazid (anti-tubercular drug) induced toxicity. Two lesions were unilateral, one was diffuse well-defined and involving most of the cord parenchyma: and one lesion was symmetrical with bilateral parenchymal involvement. Follow up study was done in three cases. Two patients showed progressive gradual clinical improvement. One patient showed relatively rapid recovery by being weaned out of ventilator. One patient was lost in follow up but the typical imaging pattern clinched the diagnosis. Two patients were excluded from this study, one with a large cortical-subcortical supratentorial lesion appearing to be a TB lesion and the other traumatic patient with a intramedullary lesion in cervical cord without a target sign, as follow up was not available. Typical signal characteristics, location and enhancement in routine and advanced techniques of MRI were the key points in identifying these atypical lesions.

\subsection{Case 1}

A 60 years old immunocompetent male patient presented with acute onset of hemiplegia with a history of gradual, progressive weakness of left half of body over three to four months. Patient's clinical condition worsened and he was put on ventilator. MRI imaging revealed a subcortical tuberculoma (which was diagnosed a few months back as a primary TB focus). In addition to tuberculoma, MRI shows typical features of encephalitis with restricted diffusion (image 4) on DWI in the parietal-frontal-insula-medial temporal cortices on the rightside, with subcortical tuberculoma, without meningeal enhancement with no typical tubercular meningitis features. Patient was treated with antitubercular therapy. CSF analysis was not done. Patient showed good recovery and was subsequently discharged for OPD follow up (Figure 1). 


\subsection{Case 2}

A 16 years old immunocompetent female patient presented with a history of gradual, progressive weakness of left limbs. Patient had no primary TB focuses. On MRI imaging, there is a large heterogeneous right thalamic mass (tuberculoma) showing T2WI hypointensity (image 1) and T1WI iso-hypointensity (image 2) with contrast enhancement (image 3) with areas of necrosis. There was no intralesional hemorrhage or calcification on SWI. Mildly elevated choline and presence of Lip-Lac peak were seen on multivoxel MR spectroscopy. Perfusion imaging obtained during a contrast study revealed no increase in rCBF. Biopsy was advised by clinician which was refused or delayed by the patient. Patient was treated with antitubercular therapy. Patient showed gradual clinical improvement. The lesion on follow up after five to six months of antitubercular therapy showed marked resolution on T2WI MRI imaging. The patient was advised to take a full course of antitubercular therapy (Figure 2).

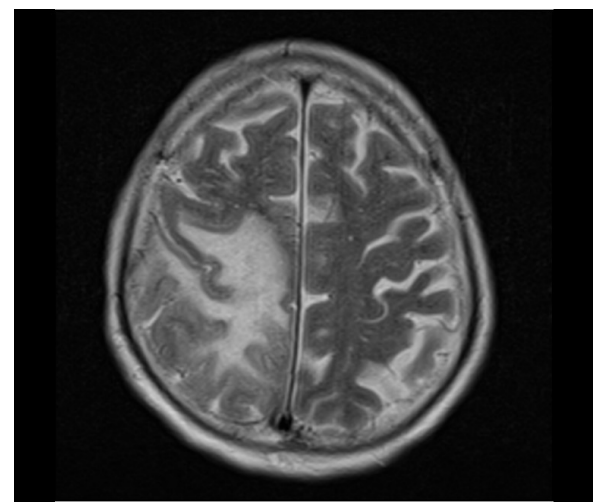

(1)

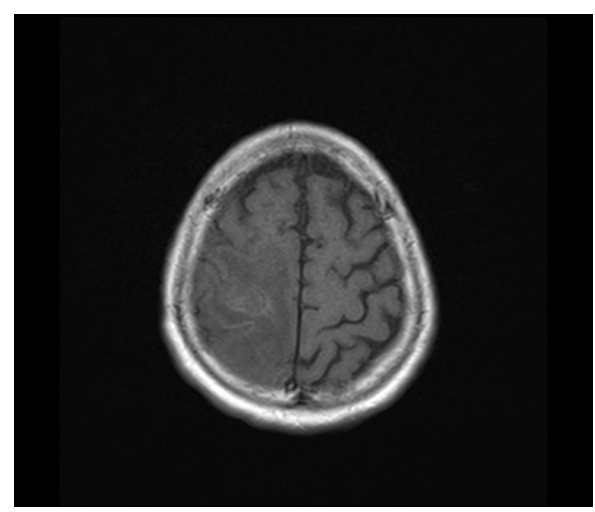

(3)

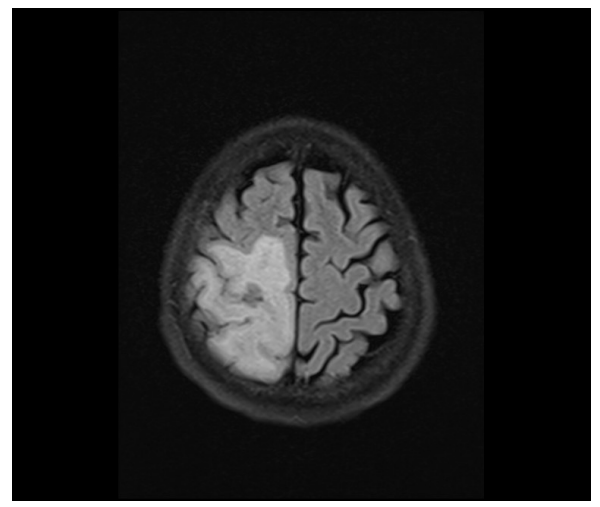

$(2)$

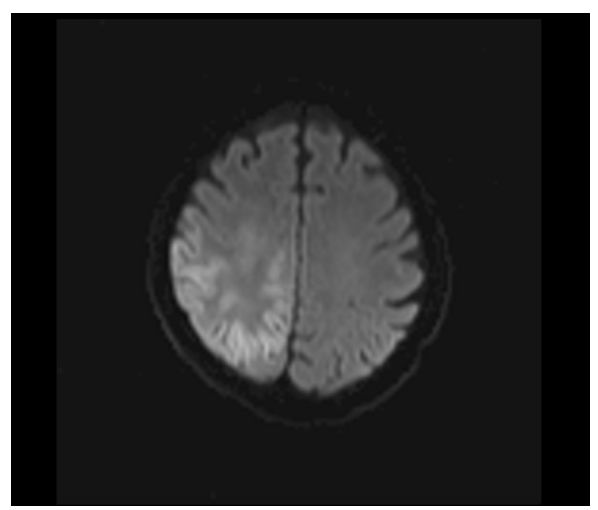

(4)

Figure 1. There is a subcortical tuberculoma (which was diagnosed few months back). In addition to tuberculoma, MRI shows typical features of encephalitis with restricted diffusion (image 4) on DWI in parietal-frontal-insula-medial temporal cortices on rightside, with subcortical tuberculoma, without meningeal enhancement.

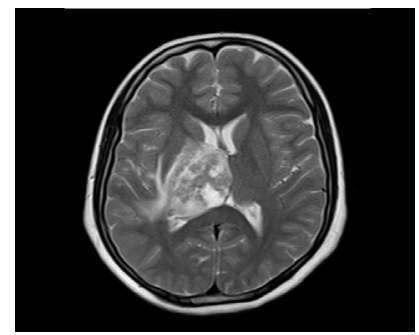

(1)

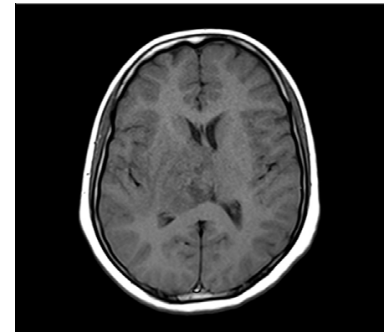

(2)

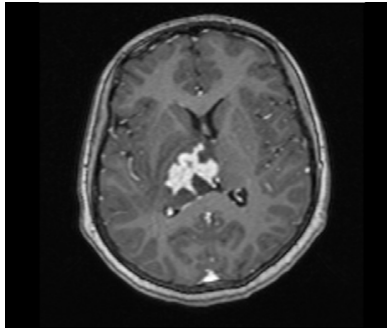

(3)

Figure 2. There is a large heterogeneous right thalamic mass (tuberculoma) showing T2WI hypointensity (image 1) and T1WI iso-hypointensity (image 2) with contrast enhancement (image 3) with areas of necrosis. 


\subsection{Case 3}

A 20 years old immunocompetent female patient presented with gradual, progressive lower limb weakness. Patient was on treatment for pulmonary TB (primary focus) for the last five months. On MRI imaging, there is an intramedullary thick ring enhancing lesion at C5-C6 level with characteristic TARGET sign (images 1 - 2) on T2WI, representing central caesation of tuberculoma. The lesion is iso-hypointense on T1WI. Biopsy was advised by clinician which was refused or delayed by the patient. The lesion shows marked resolution on follow up T2WI MRI study after three to four months of antitubercular therapy (image 4). Patient recovered completely after a full course of antitubercular therapy (Figure 3).

\subsection{Case 4}

A 43 years old immunocompetent male patient presented with acute onset of slurring of speech.The patient suffered from tubercular arthritis and was on antitubercular therapy, which included isoniazid drug. Patient also had underlying deranged renal parameters and was on hemodialysis. MRI imaging showed symmetrical T2WI hyperintensity in bilateral dentate nuclei (image 1). There was no restricted diffusion on DWI. There was no calcification or hemorrhage on SWI. The diagnosis of isoniazid induced toxicity (isoniazid induced cerebellitis) was made in view of typical MRI findings and appropriate clinical settings. Patient was lost in follow up (Figure 4).

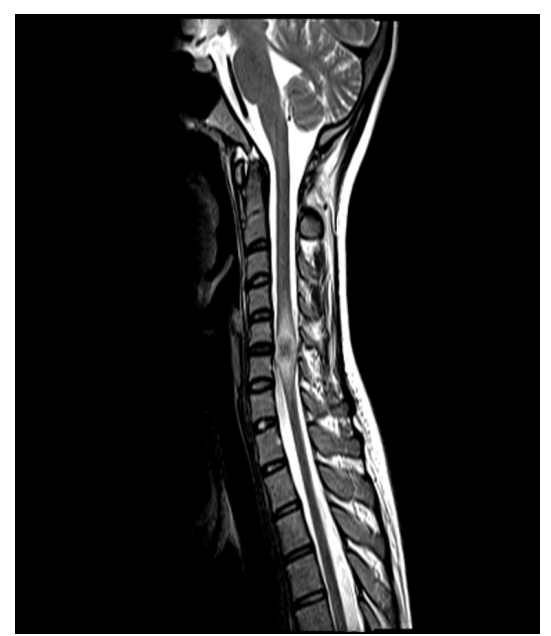

(1)

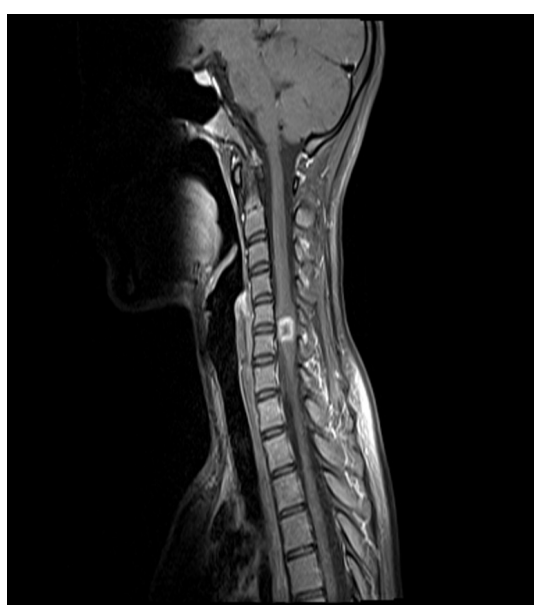

(3)

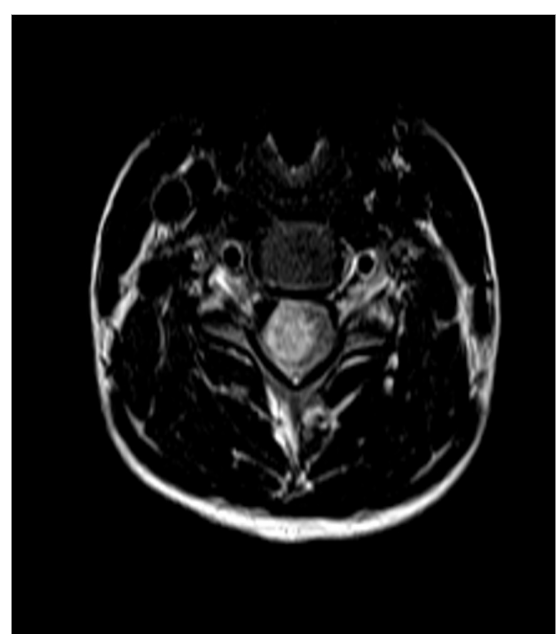

(2)

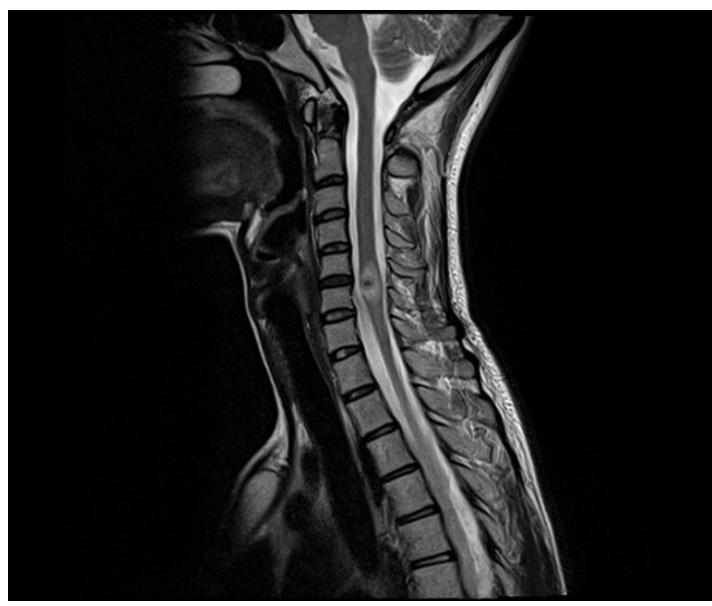

(4)

Figure 3. There is an intramedullary thick ring enhancing lesion (image 3) at C5-C6 level with characteristic TARGET sign (images 1 - 2) on T2WI, representing central caesation of tuberculoma. The lesion is iso-hypointense on T1WI. There is marked resolution on follow up T2WI (image 4). 


\section{Discussion}

This case series studies the spectrum of atypical Tubercular lesions of CNS seen over a period of four years. Arseni et al. studied 38, 510 patients treated with antitubercular drugs in a span of 22 years (1935-1957) [1]. Atypical tubercular lesions of the CNS were seen in all age groups (Table 1) and with equal gender distribution (Table 1), in this study. Pulmonary or other extracranial as well as intracranial typical TB focuses (Table 1) were present prior to development of atypical lesions in most of the cases in this study. Routine MRI study (Table 1) was sufficient in most of these cases for establishing the diagnosis. However, in case study 2, MR spectroscopy was required to confirm the infectious nature of the lesion over tumor with MR perfusion acquired

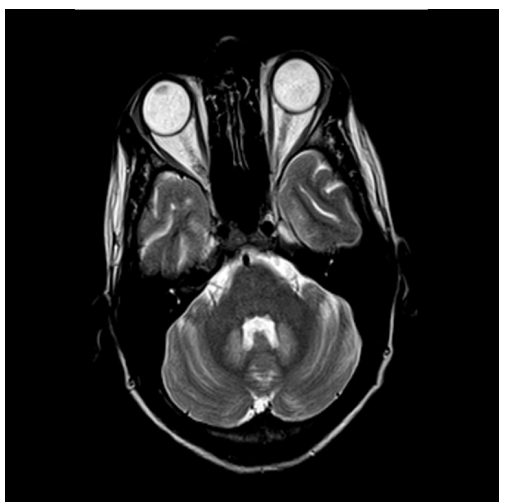

(1)

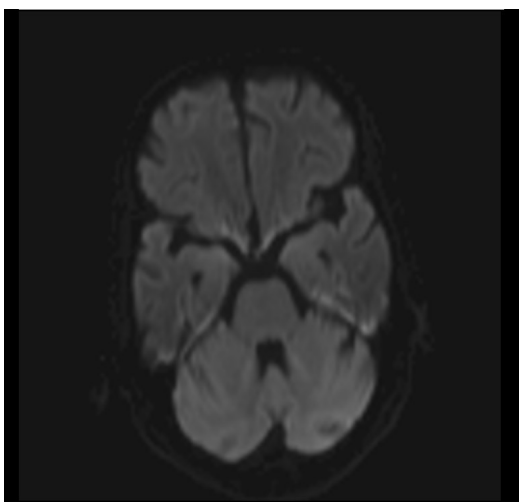

(2)

Figure 4. There is symmetrical T2WI hyperintensity in bilateral dentate nuclei (image 1). There was no restricted diffusion on DWI (image 2).

Table 1. Demographic, clinical findings, MRI imaging features and follow up of 4 patients with atypical TB lesions.

\begin{tabular}{|c|c|c|c|c|c|c|c|c|c|c|}
\hline Case Study & $\begin{array}{l}\text { Age } \\
\text { (yrs) }\end{array}$ & Sex & $\begin{array}{l}\text { Immuno } \\
\text { competent } \\
\text { status }\end{array}$ & $\begin{array}{l}\text { Clinical } \\
\text { Findings }\end{array}$ & $\begin{array}{l}\text { CSF } \\
\text { Study }\end{array}$ & $\begin{array}{l}\text { Primary TB } \\
\text { Lesion }\end{array}$ & $\begin{array}{c}\text { MRI } \\
\text { Technique }\end{array}$ & MRI Findings & Biopsy & $\begin{array}{c}\text { Follow up } \\
\text { Status }\end{array}$ \\
\hline $\begin{array}{c}\text { 1. Tubercular } \\
\text { encephalitis } \\
\text { without } \\
\text { meningitis }\end{array}$ & 60 & M & $\begin{array}{l}\text { Immune } \\
\text { competent }\end{array}$ & $\begin{array}{c}\text { Increasing } \\
\text { weakness of left } \\
\text { half of body with } \\
\text { acute onset of } \\
\text { leftsided } \\
\text { hemiplegia. No } \\
\text { pulmonary focus. }\end{array}$ & $\begin{array}{l}\text { Not } \\
\text { done }\end{array}$ & $\begin{array}{c}\text { Cns } \\
\text { tuberculoma }\end{array}$ & Routine & $\begin{array}{c}\text { Tuberculomas } \\
\text { with } \\
\text { encephalitis. }\end{array}$ & Not done & $\begin{array}{c}\text { Discharged } \\
\text { satisfactorily. }\end{array}$ \\
\hline $\begin{array}{c}\text { 2. Large } \\
\text { tubercular } \\
\text { parenchymal } \\
\text { mass }\end{array}$ & 16 & $\mathrm{~F}$ & $\begin{array}{c}\text { Immune } \\
\text { competent }\end{array}$ & $\begin{array}{c}\text { Gradual } \\
\text { progressive } \\
\text { weakness of left } \\
\text { upper and lower } \\
\text { limbs. }\end{array}$ & $\begin{array}{l}\text { Not } \\
\text { done }\end{array}$ & None & $\begin{array}{l}\text { Routine } \\
\text { with } \\
\text { advanced. }\end{array}$ & $\begin{array}{l}\text { Right thalamic } \\
\text { mass with } \\
\text { mildly elevated } \\
\text { chol. }\end{array}$ & $\begin{array}{l}\text { Advised, but } \\
\text { delayed } \\
\text { /refused by } \\
\text { patient. }\end{array}$ & $\begin{array}{c}\text { Marked } \\
\text { resolution } \\
\text { of mass after } \\
\text { AKT. }\end{array}$ \\
\hline $\begin{array}{l}\text { 3. Intramedullary } \\
\text { spinal } \\
\text { tuberculoma }\end{array}$ & 20 & $\mathrm{~F}$ & $\begin{array}{c}\text { Immune } \\
\text { competent }\end{array}$ & $\begin{array}{l}\text { Patient has } \\
\text { pulmonary TB on } \\
\text { treatment. Now } \\
\text { presented with } \\
\text { gradual onset of } \\
\text { lower limb } \\
\text { weakness. }\end{array}$ & $\begin{array}{l}\text { Not } \\
\text { done }\end{array}$ & $\begin{array}{c}\text { Pulmonary } \\
\text { TB }\end{array}$ & Routine & $\begin{array}{l}\text { Intramedullary } \\
\text { tuberculoma at } \\
\text { C5-C6 level. }\end{array}$ & $\begin{array}{l}\text { Advised, but } \\
\text { delayed } \\
\text { /refused by } \\
\text { patient. }\end{array}$ & $\begin{array}{l}\text { Marked } \\
\text { resolution of } \\
\text { lesion after } \\
\text { AKT. }\end{array}$ \\
\hline $\begin{array}{l}\text { 4. Isonazid } \\
\text { cerebellitis }\end{array}$ & 43 & M & $\begin{array}{l}\text { Immune } \\
\text { competent }\end{array}$ & $\begin{array}{l}\text { Patient had } \\
\text { tubercular arthritis } \\
\text { on treatment. } \\
\text { Underlying highly } \\
\text { deranged renal } \\
\text { parameters. } \\
\text { patient had acute } \\
\text { onset of slurred } \\
\text { speech. }\end{array}$ & $\begin{array}{l}\text { Not } \\
\text { done }\end{array}$ & $\begin{array}{c}\text { Tubercular } \\
\text { arthritis }\end{array}$ & Routine & $\begin{array}{c}\text { Bilateral } \\
\text { symmetrical } \\
\text { T2/Flair dentate } \\
\text { nuclei } \\
\text { hyperintensity. }\end{array}$ & Not advised. & $\begin{array}{l}\text { Patient lost in } \\
\text { follow up. }\end{array}$ \\
\hline
\end{tabular}


during the routine contrast study revealing no increased rCBF within the lesion. These lesions occurred in immunocompetent status (Table 1) in this study, although immunocompromised patients have a higher incidence of CNS tuberculosis.

One of the atypical forms of tubercular involvement of CNS is tubercular encephalitis. This is first highlighted in a study by Jinkins JR, where only five cases were reported in the span of 10 years [2]. Although the focal form of tuberculous cerebritis should be synonymous with focal tuberculous encephalitis, the term needs pathological clarification. Tubercular encephalopathy is a distinct clinicopathological entity. A study in France revealed high mortality with TB encephalitis [3], as compared to our case 1 where early diagnosis resulted in fast clinical recovery from comatose status. Tubercular encephalitis is characterized by absence of typical tubercular meningitis features on imaging, with or without clinical symptoms/signs and cerebro-spinal fluid changes, with imaging features predominantly revealing focal or diffuse cerebral lesions representing tubercular encephalitis without meningitis, and which have been recognized earlier [4]. Tubercular encephalitis results from blood borne transmission or from underlying tuberculoma (as in case 1). MRI and computed tomographic studies are very useful in the diagnosis, with additional confirmation with CSF studies [5].

Tubercular large intraparenchymal mass (tuberculoma) is rare. The first case report of tuberculoma was done by John Abercrombie in 1828 [6]. There were only 3\% of 210 tuberculomas, which had an exceptional size (60 to $100 \mathrm{~g}$ ) in a study by Arseni et al. [1]. Such lesions infiltrate into grey-white matter of varying degree or is located deep in the brain (as in case 2) and pose a great challenge in differentiating from CNS tumors. The heterogeneity of lesion, T2WI hypointensity, spectroscopy revealing mildly elevated choline and Lip-Lac peaks in case 2, favors infectious disease as compared to high grade glioma. Extraaxial location can simulate meningioma, lymphoma, sarcoidosis etc. In case 2 the mass was in contact with the ventricular wall with mass effect on the ventricle. About $45 \%$ the tuberculomas were found to be in contact with the meninges of the ventricles, in a study by Arseni et al. [1].

Spinal intramedullary tuberculoma is rare, accounting for $2 / 100,000$ of cases of tuberculosis and only $2 \%$ of all cases of tuberculosis of the central nervous system [7]. There were 210 cases of CNS tuberculomas in which only five were intramedullary spinal tuberculomas, in a span of 22 years (1935-1957), in a study by Arseni et al. [1]. In this case series in a span of four years, only two atypical CNS tuberculomas were found, of which only one was located in anintramedullary spinal cord region, with a ratio of intramedullary atypical tuberculoma to intracerebral atypical tuberculoma being 1:1. The ratio of intramedullary tuberculoma to intracerebral tuberculoma is approximately $1: 42$, and $72 \%$ of lesions are located in the thoracic cord [8]. Spinal intramedullary tuberculoma is mostly induced by hematogenous dissemination or cerebro-spinal fluid infection; however, in a few cases, it is caused by local spreading of spinal tuberculosis [7]. These lesions occurred in relatively young patients (mean age, 28.6 years) and more frequently in women (63\% of cases) than in men [9] as is seen in case 3. Intramedullary tuberculomas pose a challenge in differentiating from spinal cord tumors. Characteristic "target sign" clinches the diagnosis of tuberculoma among other differentials, thereby initiating a conservative line of management as is noted in case 3. The Target sign shows typical thick rim hypointensity lesion with core hyperintensity (central caseation), on T2WI images. There are three types of intramedullary spinal tuberculomas [10], of which the lesion with target sign is highly suggestive of tuberculoma [11].

Antitubercular drug induced neurotoxicity is known to occur. Isonazid cerebellitis is a rare and is diagnosed by exclusion, as in our case 4. Isoniazid induced toxicity was reported by Blumberg and Gil in 1990 [12]. Later few cases have been reported in patients with severe renal failure on hemodialysis (as seen in our case). The common form of isoniazid induced toxicity is usually acute cerebellitis where diffuse edema is present, difficult to differentiate from infectious causes. Atypical form of presentation is also recently described, as noted in case 4 [13]. MRI manifestation includes T2WI hyperintensity in dentate nuclei, symmetrical and bilateral with no restricted diffusion as seen in case 4 [14].

\section{Conclusion}

The conclusion of this study was that atypical TB lesions of CNS which were promptly diagnosed and managed had good clinical outcomes (as seen in three cases). Given the large No. of TB cases worldwide, cases with atypical presentation would account for a significant proportion. Prompt diagnosis and management would reduce mortality, morbidity and patient cost care. 


\section{Acknowledgements}

The author is grateful to Dr. Swati Sharma, for her suggestions in writing this manuscript.

\section{References}

[1] Arseni, C. (1958) Two Hundred and One Cases of Intracranial Tuberculoma Treated Surgically. Journal of Neurology, Neurosurgery \& Psychiatry, 21, 308-311. http://dx.doi.org/10.1136/jnnp.21.4.308

[2] Jinkins, J.R. (1988) Focal Tuberculous Cerebritis. American Journal of Neuroradiology, 9, 121-124.

[3] Honnorat, E., De Broucker, T., Mailles, A. and Stahl, J.P. (2013) Le Comité De Pilotage Et Groupe Des Investigateurs. Encephalitis Due to Mycobacterium tuberculosis in France. Médecine et Maladies Infectieuses, 43, 230-238. http://dx.doi.org/10.1016/j.medmal.2013.05.003

[4] Dastur, D.K. and Udani, P.M. (1966) The Pathology and Pathogenesis of Tuberculous Encephalopathy. Acta Neuropathologica, 6, 311-326. http://dx.doi.org/10.1007/BF00688161

[5] Glaser, C.A., et al. (2003) In Search of Encephalitis Etiologies: Diagnostic Challenges In the California Encephalitis Project, 1998-2000. Clinical Infectious Diseases, 36, 731-742. http://dx.doi.org/10.1086/367841

[6] Abercrombie, J. (1828) Pathological and Practical Researches on Disease of the Brain and the Spinal Cord. Waugh and Innes, Edinburg, 371-372.

[7] Lu, M. (2010) Imaging Diagnosis of Spinal Intramedullary Tuberculoma: Case Reports and Literature Review. Journal of Spinal Cord Medicine, 33, 159-162.

[8] Nussbaum, E.S., Rockswold, G.L., Bergman, T.A., Erickson, D.L. and Seljeskog, E.L. (1995) Spinal Tuberculosis: A Diagnostic and Management Challenge. Journal of Neurosurgery, 83, 243-247. http://dx.doi.org/10.3171/jns.1995.83.2.0243

[9] MacDonnell, A.H., Baird, R.W. and Bronze, M.S. (1990) Intramedullary Tuberculomas of the Spinal Cord: Case Report and Review. Reviews of Infectious Diseases, 12, 432-439. http://dx.doi.org/10.1093/clinids/12.3.432

[10] Lin, J., Feng, H., Ai, S. and Wang, X. (2006) Intramedullary Cervical Tuberculoma. Spinal Cord, 44, 809-812. http://dx.doi.org/10.1038/sj.sc.3101896

[11] Sharma, M.C., Arora, R., Deol, P.S., Mahapatra, A.K., Sinha, A.K. and Sarkar, C. (2002) Intramedullary Tuberculoma of the Spinal Cord: A Series of 10 Cases. Clinical Neurology and Neurosurgery, 104, 279-284. http://dx.doi.org/10.1016/S0303-8467(01)00196-2

[12] Blumberg, E.A. and Gil, R.A. (1990) Cerebellar Syndrome Caused by Isoniazid. DICP, 24, 829-831.

[13] Peter, P. and John, M. (2014) Isoniazid-Induced Cerebellitis: A Disguised Presentation. Singapore Medical Journal, 55, E17-E19.

[14] Sharma, P. Isoniazid Cerebellitis. http://www.ajnr.org/site/imgquiz/03092015qz.xhtml

\section{Abbreviations}

TB, Tuberculosis, OPD, Outpatient department, MRI and MR, Magnetic resonance imaging, CNS, Central nervous system. 